\title{
(20) \\ A CRÍTICA DO JOVEM SCHELLING À TEOLOGIA DE TÜBINGEN NO CONTEXTO DA QUERELA DO PANTEÍSMO
}

Resumo: O texto procura reconstruir os principais momentos da crítica de Schelling à chamada teologia ortodoxa de Tübingen. Em sua correspondência com Hegel, bem como em seus textos de juventude, Schelling procura mostrar ao amigo por que essa sua crítica à teologia se liga ao fato de ele ter "se tornado um espinosista", o que insere o debate na chamada querela do panteísmo, iniciada pelo livro de Jacobi sobre Espinosa. Embora, em sua maior parte, siga o caminho de Fichte na interpretação da obra de Jacobi, Schelling ousa ir além do autor da Doutrina-da-ciência ao igualar Deus ao eu absoluto.

Palavras-chave: filosofia, teologia, teoria da revelação, postulados da razão prática, querela do panteísmo.

Numa carta escrita de Tübingen em 4 de fevereiro de 1795, Schelling faria uma surpreendente revelação a Hegel, seu ex-companheiro de Instituto, no que se refere à sua mais nova linha de investigações filosóficas. Estando afastados um do outro por quase dois anos - depois de se formar no Instituto de Tübingen em 1793 Hegel havia assumido um cargo de preceptor em Berna -, a revelação não deixa de surpreender o futuro autor da Fenomenologia do Espírito: "Durante este período, me tornei espinosista!” (in: Hegel 4, p.22) ${ }^{1}$ - escreve Schelling a ele, mostrando até que ponto o famoso livro de Friedrich Heinrich Jacobi, Sobre a doutrina de Espinosa em Cartas ao senhor Moses Mendelssohn, o havia 
impressionado. Mas, como se veria ao longo dessa correspondência entre ambos, bem como pelas obras de juventude de Schelling, esse entusiasmo pela chamada querela do panteísmo - ocasionada pelo livro de Jacobi tinha um interesse bem delimitado: sentindo-se coagido pela interpretação às avessas que os teólogos de Tübingen começaram a fazer da filosofia prática de Kant, a leitura do livro de Jacobi teria vindo em muito boa hora. Não tanto porque Schelling concordasse com as críticas que o autor do Woldemar fazia ali contra o mais novo racionalismo (a filosofia de Kant e de Fichte) - em verdade se dava o contrário! - mas antes porque, pela primeira vez, o filósofo pôde ver, por meio delas, em que medida a filosofia de Espinosa poderia lhe ser útil no que se refere a seus projetos de salvar a nova filosofia transcendental - tal como ela surgia com Fichte - dos ataques provindos dos igualmente recentes teólogos de Tübingen.

Para poder mostrar como Schelling desenvolve essa crítica à teologia, entretanto, será preciso fazer um trajeto consideravelmente longo, passando por algumas considerações acerca do ambiente do Instituto em torno de 1790, depois a uma breve análise da interpretação da teologia sobre a filosofia prática de Kant, para somente então ser possível abordar, com mais propriedade, o modo como a crítica de caráter espinosista de Schelling surge como um desdobramento necessário dos pressupostos mais fundamentais da filosofia de Fichte.

\section{O Instituto de Tübingen em torno de 1790}

Considerada à época uma universidade pequena, constituída em sua maior parte de teólogos e futuros professores ginasiais, o Instituto de Tübingen havia se tornado há muito tempo responsável pela formação da força de trabalho de quase todo o serviço estatal e eclesiástico daquela região da Alemanha: a Suábia ${ }^{2}$. Regida pelo Duque Carlos Eugênio de
1737 a 1793 de forma absoluta, o Instituto nutria um forte orgulho de seu caráter extremamente conservador, prezando pela conservação do "bom e antigo espírito". Nessa sua disposição, fechava-se a toda e qualquer influência externa e procurava, por meio de estatutos sempre muito rígidos, contrapor-se às inovações que começavam a afluir de toda parte, principalmente da França recém-tomada pelos ares da Revolução. Esse espírito de liberdade dos novos tempos, entretanto, apesar do esforço dos dirigentes de contê-lo a qualquer custo, acabou por invadir os corredores do Instituto, sobretudo as notícias de que a França havia sido libertada do regime monárquico, absolutista e despótico que por tanto tempo havia reinado ali. Inflamados por esses rumores revolucionários, os estudantes formaram uma forte oposição ao Duque e ao seu Consistório, oposição essa que acabou por se transformar em constantes boicotes às aulas e em pequenas insurreições internas.

Mas a causa dessas insurreições dos alunos não residia apenas nessa repressão social-psicológica, mas também e acima de tudo na repressão intelectual. Pois, em sua maioria teólogos, os professores do Instituto haviam, num primeiro momento, decidido simplesmente ignorar a filosofia de Kant, apesar da fama repentina que o aparecimento dessa filosofia havia trazido a esse filósofo em toda a Alemanha. A filosofia de Kant, com efeito, parecia concordar com os acontecimentos revolucionários da França, ameaçando ao mesmo tempo teoricamente a doutrina religiosa ensinada a ferro e a fogo no Instituto, conhecida como teoria da revelação divina (Offenbarung). Baseada nos dogmas da teologia ortodoxa, essa teoria defendia que a existência de Deus havia sido revelada tanto pelas Escrituras Sagradas como pelos milagres de Cristo. Nessa medida, Deus não deveria ser compreendido pela razão, mas deveria ser considerado pura e simplesmente um objeto de fé. Tal como havia acontecido com os rumores da revolução, entretanto, também a filosofia de Kant acaba 
penetrando as muralhas do Instituto, chegando aos estudantes de forma clandestina, principalmente por meio do chamado Allgemeine LiteraturZeitung. Editado no círculo kantiano de Göttingen, esse periódico tinha justamente o objetivo de espalhar o pensamento kantiano por toda a Alemanha e defendê-lo contra as críticas de outras escolas filosóficas.

Mas como indica Horst Fuhrmans (Cf. Fuhrmans 3, p.17-8), os estudantes do Instituto a essa época não entraram em contato apenas com as Críticas de Kant, mas também com os livros de Rousseau, com Os bandoleiros de Schiller, com as poesias de Schubart sobre os despotismos ducais, com os hinos de Klopstock ${ }^{3}$ e também com as teorias de Winckelmann sobre a antiguidade grega como o lugar da mais perfeita harmonia (em clara oposição ao ambiente conflitante que havia se estabelecido dentro do Instituto). Justamente por volta desse período, Hölderlin escreve à mãe dizendo ter lhe caído "nas mãos escritos de e sobre Espinosa, um homem grande e nobre do século passado e na verdade um negador de Deus, segundo conceitos mais precisos" (Hölderlin 8, p.78) ${ }^{4}$. Como mostra Dieter Henrich (Cf. Henrich 6, p.163), esses "escritos de e sobre Espinosa" não se referem apenas ao polêmico livro de Jacobi, o Sobre a doutrina de Espinosa, mas também ao Ardinghello, romance recém-publicado de Wilhelm Heinse fortemente influenciado por esse renascimento de Espinosa no final do século XVIII na Alemanha. Como se pode ver pelos primeiros escritos filosóficos de Schelling, esse renascimento do espinosismo proporcionado por Jacobi e também por Heinse acabaria constituindo uma das principais ferramentas para a sua crítica ao pensamento teológico do Instituto.

$\mathrm{Na}$ correspondência do começo de 1795, com efeito, Schelling descreve a Hegel a situação social e intelectual do Instituto, que este último, como ex-interno, já conhecia. Diferentemente do começo dos anos 1790, entretanto, quando Hegel e Hölderlin ainda estudavam ali, nesses últimos dois anos a situação dos alunos, segundo o relato de Schelling e de acordo com a história de Fuhrmans, parecia ter piorado consideravelmente. Pois, além de o Instituto ter enrijecido seu estatuto em busca de conter o comportamento "subversivo" dos estudantes, a tática dos teólogos em relação à filosofia kantiana não se limitava mais em simplesmente ignorá-la, como, de resto, havia sido o caso desde o final dos anos 80 e começo dos 90 . Ao perceberem que seria impossível ignorar essa filosofia, dado o seu forte clamor após 1790 em todos os círculos intelectuais da Alemanha, os teólogos passam também a estudá-la e a ensiná-la em suas aulas. Ora, é então justamente nesse momento que Schelling escreve a Hegel dizendo ter surgido ali, subitamente, "kantianos aos montes" (in: Hegel 4, p.13) 5 . Como se pode suspeitar, entretanto, essa recepção que os teólogos fazem de Kant não se dá de modo espontâneo e sem interesse, mas por meio da disputa teológicofilosófica em torno do tema das provas da existência de Deus, ponto central do ataque que a filosofia de Kant havia feito à própria teologia (Cf. Henrich 7, p.188). Tendo se tornado famoso pela publicação de artigos e resenhas no Tübingische Gelehrte Anzeigen em oposição ao círculo de Göttingen, Johann Friedrich Flatt, professor de filosofia do Instituto, junta seus esforços com Gottlob Christian Storr, o teólogo talvez mais conhecido da Alemanha à época, para procurar insuflar um novo alento à teologia agonizante. Esses esforços conjuntos, com efeito, acabam por desembocar em uma interpretação peculiar da filosofia de $\mathrm{Kant}^{6}$, segundo a qual seu espírito, por assim dizer, ia ao encontro das doutrinas da teologia ortodoxa ensinadas no Instituto. Em outros termos, tendo se tornado impossível ignorar a filosofia kantiana, os professores de Tübingen também passam a ser kantianos, mas de um tal modo que "a teologia, que já tinha começado a se tornar febril, logo começa a retornar mais sadia e mais forte do que nunca" (in: Hegel 4, p.14) ${ }^{7}$, completaria Schelling na mesma carta a Hegel mencionada acima. Mas a pergunta que se deve agora fazer é: em que consistia, afinal, essa interpretação peculiar da filosofia kantiana? 


\section{A interpretação teológica da moral kantiana}

Se, por um lado, a teoria da revelação ensinada no Instituto era contradita pela filosofia de Kant, na medida em que esta fundamentava uma autonomia da razão em relação à fé, por outro, a própria filosofia kantiana fornecia, em sua Crítica da razão prática, um pendant dessa autonomia na chamada teoria dos postulados da razão prática. Segundo Kant, a razão jamais poderia chegar a conhecer Deus no plano da teoria, vale dizer, por meio de provas racionais metafísicas. Mas, no terreno das necessidades (Bedürfnis) práticas da razão, a ideia de Deus deveria ser de algum modo readmitida no sistema e, na verdade, como uma ideia do sumo bem (höchstes Gut). Essa readmissão, bem compreendida, não representaria nenhum ganho teórico para a razão no que se refere ao conhecimento de Deus, respeitando os ensinamentos da Crítica da razão pura. Mas, vindo suprir uma necessidade unicamente prática da razão - aquela do aperfeiçoamento moral infinito - essa ideia deveria ser considerada apenas visando esse aperfeiçoamento, sem trazer com isso nenhum ganho para o plano teórico. Na medida em que a razão prática trata da determinação da vontade pela lei moral, seu objeto tem de ser o sumo bem, definido como a "conformidade plena" da vontade à lei moral, mesmo que essa conformidade seja efetivamente impossível nesse domínio do ser moral finito.

Visando, porém, o aperfeiçoamento moral, essa conformidade plena precisa ser considerada objeto da determinação da vontade pela lei moral, pois, enquanto tal, ela permite "um progresso que avança ao infinito em direção àquela conformidade plena" (Kant 11, p.198). Essa realização prática, entretanto, na medida em que é infinita, só é possível para um ser racional infinito. Logo, escreve Kant em sua Crítica da razão prática, “o sumo bem é praticamente possível somente sob a pressuposição da imortalidade da alma", vale dizer, quando se considera esta um "postulado da razão prática pura" (Kant 11, p.198). Caracterizando, assim, o primeiro dos dois pressupostos necessários do sumo bem, o postulado da imortalidade da alma, na medida em que se faz necessário para se considerar a realização do progresso prático infinito, é chamado de elemento da moralidade.

$\mathrm{O}$ segundo elemento constituinte do sumo bem enquanto conformidade plena entre lei moral e vontade, é a felicidade. Felicidade, escreve Kant, "é o estado de um ente racional no mundo para o qual, no todo de sua existência, tudo se passa segundo seu desejo e vontade" (Kant 11, p.201). Essa felicidade, assim, depende de uma concordância plena da natureza com o seu fim e a própria lei moral, na medida em que é uma lei da liberdade, ordena, por meio de elementos determinantes, essa concordância. O ser racional finito, entretanto, justamente porque é finito, não pode, por meio da lei moral apenas, criar essa concordância plena da natureza com o seu próprio fim. Para tanto, seria preciso que ele fosse o criador da própria natureza e, em sua criação, fizesse-a de um modo tal que suas leis concordassem com sua vontade. Por isso, na realização do sumo bem, essa interconexão plena entre as leis da natureza e a sua vontade precisa ser igualmente postulada como necessária. Nas palavras de Kant, é necessário postular também "a existência de uma causa da natureza $[. .$.$] que contenha o fundamento dessa interconexão, a saber, da$ exata concordância da felicidade com a moralidade" (Kant 11, p.201-2). Pois somente postulando-se essa causa seria possível conservar o sumo bem no mundo, na medida em que essa "causa suprema da natureza" conteria uma causalidade adequada à disposição moral. Ora, essa causa, bem compreendida, é Deus, motivo pelo qual esse segundo postulado da razão prática é aquele que se refere à existência do ser supremo.

Ambos esses postulados, na medida em que se ligam necessariamente ao sumo bem, referem-se assim a um objeto e a um 
tema próprios da religião. Essa referência, entretanto, não se adequa ou não deveria se adequar com o modo pelo qual a teologia enxergava essa mesma questão, vale dizer, concluindo a existência de Deus a partir da ideia de sumo bem. Pois, para Kant, embora a ação moral exija a postulação da existência de Deus, ela o faz de um modo que se torna um dever de todo ser racional finito procurar alcançar Deus. Por isso, na medida em que a existência do sumo bem é associada ao dever, essa postulação poderia também ser denominada hipótese. Como, ainda, se refere a uma carência "do ponto de vista prático, pode chamar-se fé e, na verdade, fé racional pura, porque simplesmente a razão pura (tanto segundo o seu uso teórico como prático) é a fonte da qual ela surge" (Kant 11, p.202). De modo que, concluiria Kant,

a lei moral conduz, mediante o conceito de sumo bem enquanto objeto e fim terminal da razão prática pura, à religião, quer dizer, ao conhecimento de todos os deveres como mandamentos divinos, não enquanto sanções, isto é, decretos arbitrários, por si próprios contingentes, de uma vontade estranha e, sim, enquanto leis essenciais de cada vontade livre por si mesma mas que apesar disso têm que ser consideradas mandamentos do Ser supremo, porque somente de uma vontade moralmente perfeita (santa e benévola), ao mesmo tempo onipotente, podemos esperar alcançar o sumo bem... (Kant 11, p.208).

Não há dúvida de que essa teoria dos postulados, tal como Kant a expressa aqui, enceta uma passagem da filosofia para a religião, principalmente para a Doutrina Cristã, e é justamente dessa passagem que a teologia se serve para abordar essa filosofia a seu favor. Pois, de acordo com a teologia, essa teoria dos postulados viria justamente afirmar aquilo que a Doutrina Cristã procura mostrar em seus textos de teologia: que o fato de não se poder fornecer provas da existência de Deus apenas mostra como sua existência, já revelada por meio de Cristo e pelas Escrituras, deveria ser pura e simplesmente objeto da fé. Essa revelação, por isso, não se daria indistintamente, mas apenas para aquele que acredita que Deus existe efetivamente e que, assim, é capaz de aceitar os milagres e as Escrituras como sinais de sua existência. Aquele que, ao contrário, duvida por meio da razão da veracidade das Escrituras ou dos milagres de Cristo não seria capaz dessa fé, de onde a necessidade de opor aos seus argumentos racionais as "sanções" e os "decretos arbitrários", próprios do Dogma ${ }^{8}$. Logo, para a teologia, a fé em Cristo não é propriamente o produto de uma escolha livre do sujeito ou, como diz Kant, não se deixa determinar por liberdade, tal como se dá com a lei moral.

Mas o principal elemento dessa teoria dos postulados que escapa à teologia - certamente de modo voluntário - é a crítica que Kant incutiu nela à própria teologia e à teoria da revelação. Pois, como se pode ver pela passagem citada acima, a teoria dos postulados mostra claramente como a fé, esse elemento que a teologia considera exclusivo da religião, é no fundo derivada da razão considerada do ponto de vista de suas necessidades práticas. Enquanto tal, toda fé deveria ser denominada "fé racional pura", motivo pelo qual ela não pode conduzir necessariamente a nenhuma certeza acerca da existência de Deus. Isso, ainda, eliminaria a necessidade da arbitrariedade, da imposição do dogma tão peculiar à teologia, pois, ao se conhecer a fé filosoficamente como uma necessidade prática da razão, seria possível instituir uma religião que tivesse a liberdade por fundamento, a "vontade livre por si mesma" e não "sanções, isto é, decretos arbitrários, por si próprios contingentes, de uma vontade estranha". Como se veria posteriormente no chamado $O$ mais antigo programa de sistema do idealismo alemão, considerada desse modo, o dever de toda religião deveria ser o de responder à questão: "como deve ser criado um mundo para um ser moral?" (in: Hegel 5, p.234). 
Apesar disso, a teologia de Tübingen parecia fechar os olhos para essa crítica e para essa indicação de Kant e ver nela apenas aquilo que permitia um último suspiro ao seu velho espírito: o caráter indemonstrável da postulação da imortalidade da alma e da existência de Deus, bem como um argumento para a legitimação do uso de decretos e dogmas, passo esse que Schelling descreve a Hegel na mesma carta já citada acima:

todos os dogmas possíveis são agora carimbados como postulados da razão prática e onde nunca são suficientes provas teórico-históricas, ali a razão prática (de Tübingen) resolve os problemas (in: Hegel 4, p.14) ${ }^{9}$.

Um pouco mais tarde, Schelling faria um resumo ainda mais contundente desses intentos, segundo os quais se pretendia vestir o caráter dogmático e arbitrário das teses teológicas com a máscara da moralidade e do próprio esclarecimento. Prevendo uma sutil mudança no regulamento interno, escreve ele a Hegel retrospectivamente, sobre o clima que vigorava ali àquele período:

Ignorância, superstição e fanatismo vestiam aos poucos a máscara da moralidade e - aquilo que é ainda mais perigoso - a máscara do esclarecimento. Certamente muitos teriam em pouco tempo desejado fazer retornar os tempos da mais crassa treva; pois o círculo desta está longe dos grilhões que esse pseudo-esclarecimento havia posto em torno de nós. [...] Não se queria nenhum sábio, mas apenas teólogos e filósofos moralmente supersticiosos, que tornavam a razão irracional e satirizavam a história (in: Hegel 4, p.27) ${ }^{10}$.

\section{A recepção do livro de Jacobi sobre Espinosa}

Como se pode ver pelos primeiros escritos não apenas de Schelling, mas também de Fichte, se nasce nesse momento uma nova filosofia, esse nascimento se dá como um esforço comum por parte de ambos de superação dessas dificuldades a que não apenas a teologia de Tübingen, mas também o novo ceticismo de Schulze e Maimon, havia trazido a filosofia de Kant. Nessa empresa, entretanto, Fichte havia tomado a dianteira com o Ensaio de uma crítica a toda revelação, que, publicado em 1792 com a ajuda do próprio Kant, procura justamente desenvolver a ideia de uma religião fundada na liberdade absoluta do sujeito. Com efeito, já escrevia Fichte nesse Ensaio:

A razão dá a si mesma, independentemente de qualquer coisa fora dela, por meio de uma própria espontaneidade absoluta, uma lei; [...] ora, essa lei ordena de forma necessária e incondicionada exatamente porque é uma lei, e aí não se encontra nenhum arbítrio [...] (Fichte 1, p.32).

Ao entrar em contato pela primeira vez com essa filosofia de Fichte, Schelling se mostra claramente impressionado e entusiasmado por ela e é a partir dos esforços já iniciados pelo autor da Doutrina-daciência que ele dará início igualmente aos seus escritos críticos em relação à teologia. Essa critica, entretanto, não pode ser compreendida sem, antes, se examinar rapidamente o modo pelo qual tanto Fichte como Schelling recebem a interpretação de Jacobi sobre a filosofia de Espinosa.

Em seu livro sobre Espinosa, Jacobi, visando certamente atacar a mais recente filosofia, havia procurado mostrar por que afinal o sistema do autor da Ética seria, em comparação com todos os sistemas do racionalismo, o mais consequente de todos; que o espinosismo, em comparação com todas as outras formas possíveis de panteísmo, deveria ser considerado o mais perfeito e até o único possível, do ponto de vista sistemático. "Não existe nenhuma outra filosofia a não ser a filosofia de Espinosa" (Jacobi 9, p.23), diz Lessing no famoso diálogo que Jacobi decide contar em seu livro $^{11}$. Conforme se pode deduzir desse diálogo, ambos teriam concordado 
entre si que o conceito fundamental do espinosismo reside em um Ser a partir do qual tudo pode ser esclarecido. Ao perguntar a Jacobi qual seria, para ele, o espírito do espinosismo, responde o autor do livro:

Não foi outro a não ser o antiquíssimo: a nihilo nihil fit; que Espinosa, segundo conceitos deduzidos, examinou [...]. Segundo esses conceitos deduzidos, ele achou que, por meio de um tal surgir no infinito [Entstehen im Unendlichen] [...]; por meio de uma tal mudança no mesmo, seria posto um algo a partir do nada (Jacobi 9, p.24).

$\mathrm{Na}$ medida em que deve constituir o princípio absoluto de esclarecimento, esse Ser não necessita, assim, de nenhuma explicação de si mesmo. Ele deve, portanto, ter posto a si mesmo, ser eterno, e possuir tudo em si, pois tudo deve ser esclarecido a partir dele, tanto o pensamento como a própria extensão, os estados bem como o próprio devir. Como o entendimento não pode compreender nem no mínimo nem no máximo uma criação do nada, então ele deve ou prescindir da compreensão do mundo ou afirmar a eternidade da substância do mundo e na verdade de um modo tal que os princípios de todos os fenômenos estejam contidos nele e que o devir do mundo seja um com a mudança de estados ininterrupta e eterna do mundo (Cf. Scholz 14, p.XVIII).

Fica claro que em um tal sistema não há lugar para um ser superior, criador do mundo, pois, nesse sistema não há, em verdade, criação. O Deus espinosista é, assim, o próprio mundo considerado em toda sua autonomia, autonomia essa que justamente prostra e maravilha o entendimento. O Ser supremo não possui portanto nem entendimento nem vontade, muito embora todo entendimento e toda vontade se originem nele, o que caracteriza como antropomorfismo toda tentativa de atribuir a esse Ser uma consciência. Segundo sua forma, pois, diria Jacobi, o espinosismo é o sistema do mais consequente racionalismo e, segundo seu conteúdo, ateísmo ou deificação do mundo ou cosmoteísmo (Cf. Scholz 14, p.XIX). O conteúdo ateísta do espinosismo nasce como uma necessidade interna da forma racionalista, na medida em que o racionalismo, para Jacobi, se define como o sistema do tudo-querer-compreender (Alles-Begreifen-Wollen). Em outras palavras, o racionalismo de Espinosa é o mais consequente, pois é aquele que não reconhece nada como incompreensível.

Ora, já no primeiro parágrafo da Doutrina-da-ciência de 1794, Fichte se vê compelido, claramente devido à força do livro de Jacobi, a prestar $\operatorname{contas}^{12}$ com essa filosofia que havia aparecido subitamente como o mais consequente de todos os racionalismos. Depois de fundamentar o chamado primeiro princípio da Doutrina-da-ciência, segundo o qual: "o eu põe originariamente, pura e simplesmente, seu próprio ser", escreve o filósofo:

Para ele [Espinosa], o eu [...] não é pura e simplesmente porque é; mas porque algo outro é. - Decerto o eu é, segundo ele, para o eu - eu, mas ele pergunta: o que seria o eu para algo fora do eu. [...] Ele separa a consciência pura e a empírica. Põe a primeira em Deus, que nunca toma consciência de si, pois a consciência pura nunca chega à consciência: e a última nas modificações particulares da divindade. Assim estabelecido, seu sistema é plenamente consequente e irrefutável, porque se encontra em um campo onde a razão não pode mais segui-lo; mas é infundado, pois o que lhe dá o direito de ultrapassar a consciência pura dada na consciência empírica? (Fichte 2, p.49).

Apesar de procurar aqui mostrar por que a filosofia de Espinosa deve ser considerada um dogmatismo, Fichte não recusa a ela o mérito de ser um sistema consequente e em si mesmo irrefutável. Como já o havia 
mostrado Jacobi, também Fichte vê em seu sistema uma unidade e uma coerência perfeitas. Se, porém, há nele um erro, esse erro consiste apenas em que "ele acreditava concluir fundado em argumentos teóricos, onde era impelido meramente por uma carência prática”. Em outras palavras:

...ele acreditava estabelecer algo efetivamente dado, ao estabelecer meramente um ideal proposto, mas nunca alcançável. Reencontraremos sua unidade suprema na doutrina-da-ciência; mas não como algo que é, e sim como algo que por nós deve ser produzido, mas não pode sê-lo. Assinalo ainda que, se se transgride o eu sou, chega-se necessariamente ao espinosismo [...]; e que só há dois sistemas plenamente consequentes: o crítico, que reconhece esse limite, e o espinosista, que lhe salta por cima (Fichte 2, p.49).

Ao perceber que deveria prestar contas com a descoberta de Jacobi, Fichte, assim, chega à conclusão de que aquilo que movimentava o racionalismo consequente de Espinosa era um elemento prático e não teórico, como o seu próprio autor pensava; que o que o impelia ir além dos limites do eu penso, cujo estabelecimento havia se tornado a tarefa própria da filosofia crítica, era em verdade uma exigência prática da razão: de adequar inteiramente o mundo tal como ele é com uma ideia de como ele deveria ser $^{13}$. Ora, exatamente por isso, Schelling, vivendo no ambiente do Instituto de Tübingen, mostrou tanto entusiasmo com a filosofia de Fichte e essa interpretação que ele, via Jacobi, fazia do dogmatismo. Pois, segundo o que se viu acima, Fichte procurava fundar o criticismo não como um sistema que refutasse ou excluísse o dogmatismo, mas como um sistema que pudesse concorrer com aquele no que se refere à coerência e à necessidade interna de suas proposições. É então nesse sentido estrito que se deve compreender aquela carta de
Schelling a Hegel, citada ao início deste artigo, segundo a qual ele teria se tornado espinosista. Evidentemente, esse seu espinosismo não deve ser compreendido como um retorno efetivo à filosofia de Espinosa, mas, antes, como um meio de combater a teologia de Tübingen.

Como Schelling utilizaria essa leitura de Fichte para combater a teologia seria exposto em seus escritos filosóficos de juventude, o Sobre o eu como princípio da filosofia ou sobre o incondicionado no saber humano e as Cartas sobre o dogmatismo e o criticismo. Nestas últimas, com efeito, escreve o filósofo de que maneira deveria ser tomada a relação entre criticismo e dogmatismo, depois dos ensinamentos trazidos à luz pela filosofia de Fichte:

Se a Crítica da Razão Pura se pronunciou contra o dogmatismo, é que ela se pronunciou contra o dogmaticismo, isto é, contra um sistema do dogmatismo que é construído às cegas e sem investigação prévia da faculdade-deconhecer. A Crítica da Razão Pura ensinou ao dogmatismo como se tornar dogmatismo, isto é, um sistema do realismo objetivo, fundado em si mesmo. [...] Se se acredita que a Crítica da Razão Pura deve fundar apenas o criticismo, então, justamente nesse ponto, não há como salvá-la, ao que entendo, da acusação de inconsequência. Mas, se se pressupõe que a Crítica da Razão Pura não pertence com exclusividade a nenhum sistema, logo se descobrirá a razão pela qual ela deixa subsistir ambos os sistemas, o idealismo e o realismo, um ao lado do outro. A saber, ela vale para ambos porque vale tanto para o sistema do criticismo quanto para o do dogmatismo, e o criticismo e o dogmatismo nada mais são do que o idealismo e o realismo pensados sistematicamente. Quem leu com atenção aquilo que a Crítica diz sobre os postulados práticos deve confessar a si mesmo, com toda certeza, que ela deixa em aberto para o dogmatismo um campo no qual este pode 
construir seu edifício com segurança, e duradouramente (Schelling 13, p.15).

Evidentemente, tal como Fichte, Schelling não visa aqui tecer uma crítica ao dogmatismo - pelo contrário, ele mostra como a Crítica de Kant abriu o campo para ele -, mas, pelo contrário, apenas mostrar como a crítica de Kant objetivava na verdade aquilo que ele chama de dogmaticismo ${ }^{14}$, isto é, "um sistema do dogmatismo que é construído às cegas e sem investigação prévia da faculdade-de-conhecer". Com isso, as Críticas de Kant não constituiriam nem o sistema do criticismo nem o do dogmatismo, mas apenas um campo propedêutico que procurava justamente estabelecer os fundamentos tanto de um como do outro, pensados então como sistemas do realismo e do idealismo. A referência, ao final da citação acima, à filosofia dos postulados, não deixa então dúvidas de que o grande adversário de Schelling neste escrito era de fato a teologia de Tübingen que, por ter feito um uso indevido dos postulados de Kant, não compreendeu de que maneira ela poderia tê-los usado para se erigir como um verdadeiro sistema dogmático. Antes, por terem tentando mostrar que os postulados de Kant se voltavam contra o próprio Kant, os teólogos revelaram por fim não ter entendido o filósofo de Königsberg, motivo pelo qual se encaixariam justamente nesse dogmaticismo de que se tratava então criticar. Para mostrá-lo efetivamente, porém, seria preciso levar a cabo a filosofia de Fichte e mostrar em que sentido ela permitia justamente dar o golpe de misericórdia nesse então chamado dogmaticismo que, como se viu, pretendia derivar a fé justamente dos postulados da razão prática.

\section{O eu absoluto $=$ Deus}

Ora, uma das descobertas mais fundamentais do sistema de Fichte, como se viu, seria a seguinte: o dogmatismo difere do criticismo na medida em que pretende fundamentar o eu no objeto absoluto - aquilo que Espinosa entendia por substância -, ao passo que o criticismo pretendia fundamentar o objeto no sujeito absoluto - aquilo que Fichte chama de eu absoluto. Em termos de sistemas, entretanto, isso não significa que o objetivo do criticismo era refutar o dogmatismo, pois, como se viu pela tese de Jacobi, o dogmatismo encontrou no sistema de Espinosa sua forma mais perfeita e, por isso, irrefutável. O objetivo da filosofia de Fichte, assim, era corrigir a lacuna deixada pela Crítica de Kant que ainda impedia o sistema do criticismo de se erguer com a mesma necessidade com que, na filosofia de Espinosa, se ergueu o dogmatismo. Mas qual era, afinal, essa lacuna? Sem dúvida, o fato de Kant ter mantido o eu penso nos limites da representação, como uma representação ${ }^{15}$ e de não ter estendido esse princípio a todo o saber possível. Pois, como se viu, a Doutrina-da-ciência mostrou que a causa de o dogmático ultrapassar o eu e colocar o seu fundamento num objeto absoluto era de natureza prática e não teórica. Em outras palavras, se o criticismo pretendia fazer frente ao dogmatismo, ele não deveria permanecer apenas no plano teórico, pois, como diz Schelling, na medida em que o dogmatismo tem "um fundamento mais profundo do que a faculdade-de-conhecer", ele "zombaria de nossas provas" (Schelling 13, p.9). Assim, "o criticismo [...] só tem fracas armas contra o dogmatismo, se fundar seu sistema inteiro apenas na índole de nossa faculdade-deconhecer, e não em nosso próprio ser originário" (Schelling 13, p.8). Para poder fazer frente aos seus argumentos, por isso, o eu penso - que Kant pretendeu fundamentar apenas teoricamente - não poderia mais se limitar apenas ao âmbito da faculdade-de-conhecer. Mas, pelo contrário, ele deveria se fundamentar em algo além da mera representação, a saber, no domínio do incondicionado ou da filosofia prática.

Como explica Schelling, estender o eu penso para além da mera representação significava justamente levá-lo à esfera do absoluto, até onde 
“o princípio do ser e do pensar coincidem” (Schelling 12, p.86). Em outras palavras, seria preciso mostrar que, longe de ser apenas uma representação, esse eu é um produto do pensamento de si ou, como diz Fichte, da sua ação de pôr (setzen) a si mesmo pelo ato do pensamento. Como escreve Fichte na Doutrina-da-ciência, seria preciso tornar evidente que: "o eu põe a si mesmo e é, em virtude desse mero pôr-se por si mesmo; e vice-versa: o eu $e ́$ e, em virtude de seu mero ser, põe seu ser" (Fichte 2, p.46). Se, assim, o eu põe a si mesmo e somente é em virtude desse seu pôr-se, então ele é absoluto, pois, como diria ainda Schelling, "o absoluto somente pode ser dado por meio do absoluto" (Schelling 12, p. 86) ${ }^{16}$.

Mas a questão aqui é saber como Schelling utiliza essa fórmula de Fichte contra a teologia ou, o que é o mesmo, contra o dogmaticismo. Ora, já no seu escrito Sobre o eu é possível ver as primeiras tentativas do filósofo de utilizar essa argumentação da Doutrina-da-ciência contra as tentativas da teologia de usar os postulados da razão prática a favor da teoria da revelação de Deus. Ali, com efeito, o filósofo desenvolve pela primeira vez seu argumento segundo o qual a relação entre o particular e o absoluto, entre o homem e Deus, não pode se dar da mesma forma como se dá a relação entre sujeito e objeto. Para mostrá-lo, Schelling recorre ao conceito de intuição intelectual, recuperando o sentindo de Amor Dei intellectualis que lhe dá Espinosa na proposição 32 do livro V da Ética ${ }^{17}$. "Para ele [Espinosa], a intuição intelectual do absoluto era o supremo, o último grau de conhecimento a que pode elevar-se um ser finito, a vida própria do espírito" (Schelling 13, p.23). A intuição intelectual, com efeito, na medida em que prescinde de toda e qualquer mediação do sensível (como, aliás, já havia notado Kant), permite a passagem do finito ao infinito, do condicionado ao incondicionado, enfim, da filosofia teórica para a prática. Pois "ela se distingue de toda intuição sensível por ser produzida somente por liberdade" e ocorre "quando deixamos de ser objeto para nós mesmos e quando, retirado em si mesmo, o eu que intui é idêntico ao eu intuído" (Schelling 13, p.24).

Ao inexistir, nessa intuição intelectual do eu por si mesmo, toda e qualquer relação entre sujeito e objeto, sua ação se torna uma ação absoluta e é por meio dela, nesse momento "em que desaparecem para nós tempo e duração", que se realiza aquela passagem procurada do finito ao infinito, da filosofia teórica para a filosofia prática: a única, segundo Jacobi, que existia para o próprio Espinosa, já que "ele [Espinosa] censurou [...] aquela passagem do infinito ao finito; de modo geral, toda Causas transitorias, secundarias ou remotas" (Jacobi 9, p.24, em latim, no original).

Utilizando, assim, o exemplo do dogmatismo mais consequente, Schelling procura mostrar que também no caso do criticismo essa passagem do finito ao infinito não é possível nem pela esfera objetiva nem pela subjetiva. Mas que apenas na medida em que se parte do próprio incondicionado essa comunicação é possível, em que o eu, rompendo as barreiras do finito, alcança o absoluto por meio do simples pensamento de si mesmo, pois, na intuição intelectual, o eu se "produz a si mesmo por meio de seu pensamento, por causalidade absoluta" (Schelling 12, p. 167). Nesse ponto, Schelling parece então endereçar uma crítica ao próprio Espinosa, muito semelhante àquela de Fichte. Segundo o filósofo, se Espinosa chegou ao princípio da intuição intelectual como o princípio mais elevado de seu sistema, ele o compreendeu como uma intuição intelectual do Absoluto em que ele próprio era como que diluído. Pelo contrário, como mostraria então o sistema do criticismo, "não era ele que havia desaparecido na intuição do Absoluto, mas, inversamente, para ele tudo aquilo que se chama objetivo desaparecera nessa intuição de si mesmo" (Schelling 13, p.25). Em outras palavras, se é apenas por uma intuição de si mesmo que Espinosa teria chegado a uma intuição do Absoluto, então o fundamento do eu penso não é o objeto absoluto (a substância, em suas palavras), mas um sujeito absoluto 
que está na base de toda a relação entre sujeito e objeto e que a possibilita ${ }^{18}$. Mais uma vez, entretanto, essa sua crítica a Espinosa parece conter em si algo que não é propriamente a sua filosofia, mas o dogmaticismo da teologia de Tübingen, também definido, a esta altura de suas Cartas, como um delírio místico. Pois esse delírio, com efeito,

quando se torna sistema, não provém de nada outro, senão da intuição intelectual objetivada, de se tomar a intuição de si mesmo pela intuição de um objeto fora de si, a intuição do mundo intelectual interior pela intuição do mundo suprasensível fora de si (Schelling 13, p.25).

Que essa sua crítica tenha em vista mais a teologia de Tübingen do que o próprio Espinosa confirma-se pelo fato de que Schelling, aqui, tem em vista mostrar que o Absoluto não é um objeto fora do eu, mas, antes, um momento do próprio eu, em sua intuição de si mesmo, e que antecede ou sucede a sua autoconsciência. Nas suas palavras, dado que o Absoluto não pode se manifestar a não ser por meio do eu, então é apenas como um eu absoluto que se tem acesso a ele e nunca como um objeto absoluto, seja na forma como o considera o dogmatismo, seja na forma como o dogmaticismo da teologia de Tübingen considera Deus, esse Ser moral, transcendente ao mundo e ao eu e considerado objeto da fé. Pois, como diria Schelling já no Sobre o eu, ousando um passo consideravelmente mais além do que aquele de Fichte:

Na medida em que é determinado como objeto, Deus não pode ser para mim pura e simplesmente o fundamento real de meu ser, porque assim ele cairia na esfera do condicionado. Pelo contrário, se eu determinasse Deus não como objeto, mas como $=\mathrm{eu}$, então certamente ele seria fundamento real de meu saber (Schelling 12, p.91).
Como Deus é incondicionado por excelência, ele não pode ser determinado e conhecido da mesma forma como se determina um objeto, mas somente na esfera do próprio incondicionado. Essa esfera, entretanto, é o plano do eu absoluto, como se viu, que perfaz a esfera do ser absoluto. Logo, Deus não deve ser visto de outro modo, a não ser como o eu absoluto, pois não é possível ter acesso ao Absoluto a não ser por meio do eu absoluto. $\mathrm{O}$ modo pelo qual Schelling pretendia realizar essa equação entre o eu absoluto e a própria representação de Deus, aparece de modo mais claro na carta que ele envia a Hegel em 4 de fevereiro de 1795:

A filosofia deve partir do incondicionado. Ora, perguntase: onde repousa esse incondicionado, no eu ou no não-eu? Se se solucionar essa pergunta, soluciona-se todo o resto. - Para mim, o eu puro, absoluto é o princípio mais elevado de toda filosofia, isto é, o eu enquanto mero eu, ainda não condicionado por objeto nenhum, mas que é posto por liberdade. [...] - O eu absoluto compreende uma esfera infinita do ser absoluto e nesta formam-se esferas finitas que surgem por meio de limitações da esfera absoluta por meio de um objeto (esfera do ser - filosofia teórica). Nesta, há claramente condicionalidade, e o incondicionado conduz a contradições. - Mas nós devemos romper esses limites, isto é, devemos ultrapassar a esfera finita na infinita (filosofia prática). Esta exige, portanto, destruição da finitude e nos conduz com isso no mundo supra-sensível. [...] Mas neste, não encontramos senão nosso eu absoluto, pois somente este descreveu a esfera infinita. Não existe para nós nenhum mundo supra-sensível a não ser o eu absoluto. - Deus não é senão o eu absoluto, o eu na medida em que todo o teórico foi destruído, na medida em que a filosofia teórica é $=0$. A personalidade surge por meio da unidade da consciência. Mas a consciência não é possível sem objeto; para Deus, entretanto, isto é, para o eu absoluto, não há nenhum 
objeto, pois senão ele cessaria de ser infinito - logo, não existe nenhum Deus pessoal e nosso esforço mais elevado é a destruição de nossa personalidade, a passagem para a esfera absoluta do ser, que, entretanto, não é possivel na eternidade; - daí apenas aproximação prática do absoluto e daí - imortalidade (in: Hegel 4, p.22).

Muito poderia ser dito dessa declaração inflamada do jovem Schelling. Para ser breve, segundo o que se lê aqui, é a insuficiência da refutação teórica do dogmatismo que leva à necessidade de passar ao plano do incondicionado. Apenas rompendo-se os limites do condicionado as contradições que se apresentam na finitude podem ser resolvidas, a saber, no plano da infinitude. Ao se romper com a esfera do condicionado, entretanto, cai-se necessariamente no domínio do eu absoluto, já que o eu absoluto perfaz a esfera do ser absoluto (para além do eu absoluto não há nada). Ora, o domínio do eu absoluto, na medida em que não há nele nenhuma condição, é o domínio da liberdade. Para Schelling, assim, como Deus deve ser definido como o Ser que contém o máximo de liberdade, então o eu absoluto deve ser compreendido como o próprio Deus. Mas ao ser equiparado ao eu absoluto, esse Deus não pode ser um Deus pessoal, vale dizer, esse Ser "sentado lá em cima no céu". Pois, na medida em que é equivalente ao eu absoluto, esse Deus deixa de possuir o elemento caracterizador de toda personalidade, de toda individualidade, enfim, de toda consciência: o objeto. A grandeza de Espinosa, assim, que o criticismo soube aproveitar da sua maneira, residiria em que "enquanto intuía em si o intelectual, o Absoluto não era mais, para ele, um objeto" (Schelling 13, p. 24), motivo pelo qual sua concepção de Deus não poderia ser igualmente uma concepção personalista, antropomórfica. Antes, esse Deus, se se o considera $=$ ao eu absoluto, deve ser considerado apenas um ideal prático, inalcançável ou alcançável apenas por uma aproximação prática infinita.
Afinal, "o criticismo não tem como salvar-se da acusação de delírio místico, do mesmo modo que o dogmatismo - se, com este, ultrapassar a destinação do homem e tentar representar o alvo último como alcançável" (Schelling 13, p.29).

\section{THE YOUNG SCHELLING'S CRITICISM OF TÜBINGEN'S THEOLOGY IN THE CONTEXT OF THE PANTHEISM CONTROVERSY}

Abstract: The article attempts to show the main moments of Schelling's criticism of the ortodoxal Theology of Tübingen. In his correspondence with Hegel, as well as in his texts as a young man, Schelling tries to show to his friend why this criticism of the theology is connected to the fact that he has become an Spinozist, what inserts the debate in the so called Pantheism Controversy, started with the Jacobi's book about Spinoza. Although Schelling agrees with Fichte in his lecture of Jacobi's book, he outgoes him by equating God and the very absolute self.

Keywords: Philosophy, Theology, Revelation Theory, Practical Reason Postulates, Pantheism Controversy.

\section{REFERÊNCIAS BIBLIOGRÁFICAS}

1. FICHTE, J.G. Versuch einer Kritik aller Offenbarung. Berlin: Walter de Gruyter \& Co., 1971.

2. ___ Fundação a toda Doutrina-da-ciência. São Paulo: Abril Cultural, 1988 (trad. Rubens Rodrigues Torres Filho).

3. FUHRMANS, H. Schelling im Tübinger Stift. In: SCHELLING, F.W.J. Briefe und Dokumente, Band I, 1775-1809. Bonn: H. Bouvier und Co. Verlag, 1962.

4. HEGEL, G.W.F. Briefe von und an Hegel. Hamburg: Felix Meiner Verlag, 1952.

5.___ Frühe Schriften. Frankfurt am Main: Suhrkamp, 1986.

6. HENRICH, D. Der Grund im Bewußtsein. Stuttgart: Klett-Cotta, 1992.

7._Konstellationen. Probleme und Debatten am Ursprung der idealistischen Philosophie (1789-1795). Stuttgart: Klett-Cotta, 1986.

8. HÖLDERLIN, F. Sämtliche Werke. Frankfurt am Main: Deutscher Klassiker Verlag, 1992. 
9. JACOBI, F.H. Über die Lehre des Spinoza in Briefen an den Herrn Moses Mendelssohn. Hamburg: Felix Meiner Verlag, 2000.

10. KANT, I. Crítica da Faculdade do Juízo. Lisboa: Imprensa Nacional, 1998 (trad. Valerio Rohden e Antonio Marques).

11. Crítica da Razão Prática. São Paulo: Martins Fontes, 2002 (trad. Valerio Rohden).

12. SCHELling, F.W.J. Vom ich als Princip der Philosophie oder über das Unbedingte im menschlischen Wissen. In: Werke. Stuttgart: Froomann Holzboog, 1980.

13. Cartas sobre o dogmatismo e o criticismo. São Paulo: Abril Cultural, 1980 (trad. Rubens Rodrigues Torres Filho).

14. SCHOLZ, H. Die Hauptschriften zum Pantheismusstreit zwischen Jacobi und Mendelssohn. Berlin: Verlag von Reuther \& Reichard, 1916.

\section{NOTAS}

1. Schelling a Hegel, 4 de fevereiro de 1795. Todas as citações retiradas das obras em alemão foram traduzidas por mim.

2. A universidade mais importante da região, por outro lado, onde se formavam os médicos e os juristas, era a Karlsschule, que ficava em Stuttgart, e onde estudou, por exemplo, Schiller. Sigo adiante o relato feito por Fuhrmans 3, p.9-18.

3. A 20 de março de 1790, Hölderlin transcreve uma citação do Hino An Bodmer, de Klopstock, no Stammbuch de Immanuel Niethammer, a essa época também estudante no Instituto de Tübingen. Cf. Hölderlin 8, p.512.

4. Carta de 14 de fevereiro de 1791.

5. Schelling a Hegel, 6 de janeiro de 1795.

6. Cf. Storr, G.C. Bemerkungen über Kant's philosophische Religionslehre. Tübingen, 1794 e Süskind, F.G. Bemerkungen über den aus Principien der praktischen Vernunft hergeleiteten Ueberzeugungsgrund von der Möglichkeit und Wirklichkeit einer Offenbarung. Tübingen, 1794.

7. Schelling a Hegel, 6 de janeiro de 1795.

8. É essa necessidade de sanções e decretos que Hegel, nos seus primeiros escritos de religião, chama de positividade da religião Cristã, vale dizer, essa arbitrariedade que deve de algum modo acompanhar a fé. Cf. Hegel 5, p.112 e ss.

9. Schelling a Hegel, 6 de janeiro de 1795.

10. Schelling a Hegel, 21 de julho de 1795.

11. Teria sido este, com efeito, o elemento propulsor da querela do panteísmo, a saber, a declaração de Jacobi de que Lessing teria confessado a ele, num diálogo ocorrido no passado, ser um espinosista. A querela, na verdade, se iniciou após a morte de Lessing, quando Mendelssohn resolveu defender o contrário, passando a advogar contra o "irracionalismo" de Jacobi em favor da filosofia do esclarecimento. Cf. para isso Beckenkamp, J. Entre Kant e Hegel. Porto Alegre: EDIPUCRS, 2004, p.11-20.

12. O próprio Kant se vê compelido a prestar contas com a filosofia de Espinosa, também muito provavelmente devido ao livro de Jacobi. Cf. o $\S 73$ da Crítica da Faculdade do Juízo.

13. Essa crítica que Fichte faz a Espinosa, inclusive, havia sido feita em termos muito semelhantes por Kant, quando escreve, no $§ 73$ da Crítica da Faculdade Juízo: “Torna-se então fácil ver que Espinosa, pelo facto de reduzir os nossos conceitos da conformidade a fins na natureza à consciência do nosso próprio ser, num ser que tudo abrange (porém ao mesmo tempo simples), e por procurar aquela forma simplesmente na unidade deste último ser, teria que ter a intenção de afirmar, não o realismo, mas sim meramente o idealismo da conformidade a fins da mesma" (Kant 10, p.315).

14. Seria preciso notar aqui que a obra de Schelling foi publicada com o título errado, por confusão do seu editor que, entretanto, fez questão de anotar: "estas cartas foram publicadas, pela primeira vez, no Jornal Filosófico do ano de 1795 (onde, em vez de 'dogmatismo', se lia inicialmente 'dogmaticismo')" (Schelling 13, p.4). Em outras palavras, desde o início o título do texto seria Cartas sobre o dogmaticismo e o criticismo, em clara referência então a essa relação peculiar entre a filosofia crítica e o dogmatismo sem prévia investigação da faculdade-de-conhecer, cujo melhor exemplo era a própria teologia de Tübingen.

15. Essa é, de resto, a mesma crítica que Fichte faz a Reinhold: "Reinhold estabelece o princípio da representação, e na forma cartesiana sua proposição fundamental seria: repraesento, ergo sum ou, mais corretamente, repraesentans sum, ergo sum. Ele vai consideravelmente mais longe que Descartes; mas, se quer estabelecer a ciência mesma e não meramente sua propedêutica, não vai longe o bastante; pois mesmo o representar não é a essência do ser, e sim uma determinação particular dele..." (Fichte 2, p.48).

16. Essa argumentação, extremamente lógica, não pode ser mostrada aqui em sua 
completude. Cf. para isso o primeiro parágrafo da Fundação a toda Doutrina-daciência, Fichte 2, p.43-9.

17. "Este é o ponto mais alto de seu sistema" (Schelling 12, p.185), escreve o filósofo.

18. Para fundamentar essa afirmação, Schelling cita a proposição 30 do livro V da Ética.

\section{DEFESAS DE DOUTORADO}

\section{André Menezes Rocha}

Espinosa e a Inteligibilidade da História. Ensaios sobre a Liberdade e a

Democracia no Tratado Teológico-Político

Orientadora: Profa. Dra. Marilena de Souza Chauí

Data: 15.06.2011

Resumo: Interrogamos a escrita política de Espinosa e o sentido da definição de democracia oferecida no Tratado Teológico Político. A partir das concepções de história da Natureza e história da Escritura, no capítulo VII, buscaremos os vínculos que a escrita espinosana estabelece entre a linguagem e a politica, entre a definição de democracia e a história no capítulo XVI. Nosso propósito é demonstrar que a escrita política de Espinosa é concebida como uma instituição livre que é internamente estruturada segundo leis necessárias imanentes e pela compreensão estas leis nós poderemos verificar de que maneira Espinosa pensava as relações entre a prática discursiva livre e a prática política que institui a liberdade na República.

Palavras-chave: discurso político, liberdade, política, democracia, república. 